\title{
Detoxification effect of chlorination procedure on waste lead glass
}

\author{
Aris Erzat $\cdot$ Fu-Shen Zhang
}

Received: 24 December 2013/ Accepted: 26 June 2014 / Published online: 20 July 2014

(C) Springer Japan 2014

\begin{abstract}
This work reports the detoxification effect of chlorinating volatilization procedure on waste lead glass. The effects of various reaction parameters on lead removal efficiencies were examined, and the optimal operation conditions were $1000{ }^{\circ} \mathrm{C}, 2 \mathrm{~h}$, and $600 \pm 50 \mathrm{~Pa}$, respectively. Moreover, it was found that the residues could be safely applied in a wide range, e.g., for wollastonite synthesis by an environmental benign technique. Accordingly, the typical hazardous waste was successfully converted into a safe raw material for further industrial application.
\end{abstract}

Keywords Hazardous waste - Cathode ray tube funnel glass $\cdot$ Lead $\cdot$ Chloride volatilization $\cdot$ Wollastonite

\section{Introduction}

The amount of waste electrical and electronic equipment (WEEE) generated in the world is growing rapidly which contains hazardous components that may seriously pollute the environment if they are not properly disposed. Among them, waste cathode ray tube (CRT), the main component of a monitor, accounted for about $70 \mathrm{wt} \%$ of the total e-waste in China [1]. CRT glass supply is going to exceed the demand of CRT manufacturing in approximately 2015 which will lead to large amount of waste CRT glasses [2]. The cathode ray tube can be divided into three parts namely, (a) electron gun, (b) front panel glass, and (c) funnel glass. As containing high amount of lead, which necessary for

\footnotetext{
A. Erzat · F.-S. Zhang $(\bowtie)$

Research Center for Eco-Environmental Sciences, Chinese Academy of Sciences, 18 Shuangqing Road, Beijing 100085, China

e-mail: fszhang@rcees.ac.cn
}

absorbing the UV and $\mathrm{X}$ radiation produced by the electron gun, waste CRT funnel glass is considered as a hazardous waste [3]. Because broken lead containing glass will leach lead when mixed with acid water, land filling of this material is forbidden in most part of the world. A better solution is to detoxify this lead glass when their lifetime is attained.

It is difficult for the conventional acid leaching methods to extract lead completely from the funnel glass due to its special stable structure which is $\mathrm{PbO}(1-x) \mathrm{SiO}_{2}$ [4-6]. Previous studies focused on the enhanced leaching of lead silicate glasses so as to improve the lead extraction efficiency by breaking the glass's structure [7-12]. Furthermore, various utilizations of the CRT glasses were studied at the same time. Tung-Chai Ling [13] used recycled glass derived from CRT glass with a specific gravity of approximately $3.0 \mathrm{~g} / \mathrm{cm}^{3}$ as fine aggregate for preparing cement mortars for $\mathrm{X}$-ray radiation-shielding applications. Functional materials such as different foam glasses made by CRT glasses were investigated as well [14-16]. Longprocess time, high-energy consumption and low-lead recovery efficiency, however, limited the recycling of waste CRT glass. Chlorination is a general method widely used in the extracting of metals from their ores and industrial wastes [17]. The chlorination volatilization of fly ash has been investigated by previous reports [18-21]. However, metals in fly ash are not in an amorphous structure with $\mathrm{SiO}_{2}$ as in CRT glass. The chlorination agent releases chlorine containing gasses instead of reacting directly with metal oxides. Furthermore, the compositions of different fly ashes are not as stable as lead glass because of different raw materials during incineration. Thus the vacuum chlorination volatilization process is more effective in disposal of CRT glass than fly ash. High $\mathrm{SiO}_{2}$ containing raw materials, e.g., sewage sludge, are preferred because of thermodynamic driving force [22, 23]. 
Wollastonite has a wide range of applications in current industry. It is a largely inert material, making it a substitute for asbestos in thermal insulation applications. In ceramics, it reduces warping and cracking during firing and increases strength. Because it provides reinforcement, hardening, low oil absorption, so wollastonite is used in paint. And in textured coatings, it provides crack resistance, reinforcement, and high brightness. Wollastonite is also used in the manufacture of adhesives, joint compounds, refractories, and rubber. All grades of wollastonites are used in the production of plastics, including nylons, phenolic molding compounds, polyesters, and polyurethanes and polyureas. Some studies show that wollastonite has bioactivity and is a potential material for tissue repairing [24-26]. Current ways of manufacturing wollastonite are mainly opencast working in a low degree of mechanization, leading to environmental pollution. The residue of this study is mainly made of wollastonite, which is a novel environmental friendly way to provide wollastonite for industrial manufacture.

Our previous studies [27, 28] examined the suitability of waste CRT funnel glass as a new and efficient raw material for vacuum volatilization process. Thus far, there is no previous report on detoxification effect of chlorination volatilization process and property of its residue. In fact, the residue has broad application prospects. After deeply investigating effects of various parameters on predominant thermochemical reactions of the process, the property of the residue was examined. The residue of vacuum chlorination volatilization process is wollastonite and its physical characters are suitable for safely used as fine aggregate in architecture progress and other applications. This study provides an essential approach for waste CRT funnel glass utilization under chlorination volatilization process.

\section{Materials and methods}

Sample preparation

The waste lead containing glass employed in this study was CRT funnel glass [29], which was provided by Huaxing Environmental Protection Corporation (Beijing), was first broken into small pieces $(\leq 10 \mathrm{~mm})$ and coatings on the surface of the glass were removed by wet scrubbing and ultrasonic cleaning methods [30]. Afterwards, the CRT glass particles were dry ball milled and sieved through a 200-mesh sieve, residue particles were milled and sieved through a 40-mesh sieve, and then all powder was dried at $105{ }^{\circ} \mathrm{C}$ for $24 \mathrm{~h}$.
Experimental procedure

The residue used in the research was the solid part in the chamber after chlorination volatilization process. The milled CRT glass powder mixed with chlorination agent was loaded in the quartz crucible and placed in the process chamber. Then the mixed powder was heated by graphite heaters to the set temperature. Accordingly, pellets with chlorinating agent ratio of $35 \%$ were examined at temperatures $600,700,800,900,1000{ }^{\circ} \mathrm{C}$, and holding times were $0.5,1.0,1.5,2.0,4.0$ and $8.0 \mathrm{~h}$, respectively.

Figure 1 shows a schematic diagram of the setup used for the production. The installation consists of four basic units, i.e., heating system $(a, b, c)$, water cooling system (g, $\mathrm{h}$ ), gas installation $(i, j)$, and vacuum system $(k, 1, m)$. The chamber was evacuated by a vacuum pump to a pressure of $600 \pm 50 \mathrm{~Pa}$. Then purity argon gas $(99.9 \%)$ was blown to the chamber to remove the air in the system when no oxygen atmosphere is needed. To control the atmosphere inside the furnace and draw out the volatilized gases, gas was injected into the chamber at a rate of $200 \mathrm{~mL} / \mathrm{min}$. At sub atmospheric pressures, the pressure in the chamber was measured by a pressure gage and controlled by a vacuum valve. When each treatment was finished, the process chamber was slowly cooled down to room temperature.

Analysis

Composition of the residue and product were examined by $\mathrm{X}$-Ray Fluorescence. The collected powder was characterized by $\mathrm{X}$-ray diffraction (XRD) using the $\mathrm{Ni}$-filtered $\mathrm{Cu} \mathrm{K} \alpha$ radiation on a RigakuD/MAX2500 diffractometer. The samples were analyzed by an inductively coupled plasma optical emission spectrometer (OPTIMA 2000) after digested by $\mathrm{HNO}_{3}-\mathrm{HClO}_{4}-\mathrm{HF}$ [31]. All the experiments were duplicated triple. The measurement errors were around $\pm 1 \%$. According to the toxicity characteristic of the leaching procedure (TCLP) of USEPA, lead leaching behavior of the residues was evaluated [32]. The amount of sample was $20 \mathrm{~g}$. And the liquid solid ratio was 20:1. After adding leaching agent, the sample was leached at $22{ }^{\circ} \mathrm{C}$ for $18 \mathrm{~h}$ under $30 \mathrm{rpm}$. At the end, sample was filtered by filter membrane. The residual glass melt was coated with carbon and pictures were taken using Scanning Electron Microscope (HITACHI S-3000 N). Thermogravimetric analysis was used to identify the reaction temperature.

\section{Results and discussion}

Evaluation of reaction temperature

As can be seen in the Chemical Society of Japan [33], when the vapor pressure is below $5 \mathrm{mmHg}$, the vapor 


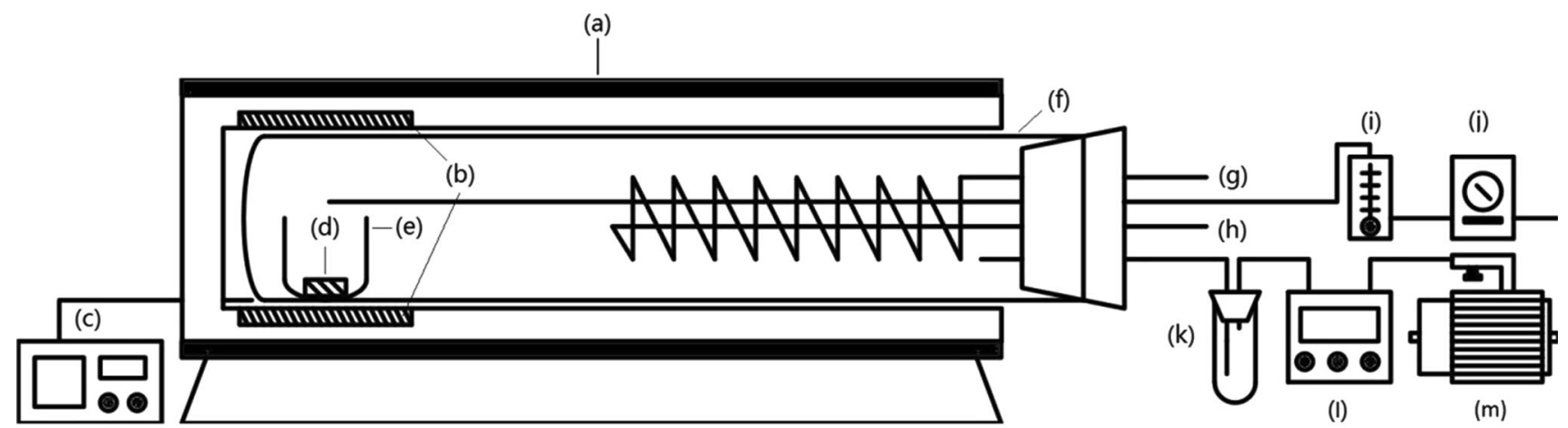

Fig. 1 Schematic diagram of the chlorinating volatilization process. $a$ chamber, $b$ graphite heaters, $c$ temperature control device, $d$ pretreated CRT pellets, $e$ crucible, $f$ quartz tube, $g, h$ inlet and outlet of water cooling device, $i, j$ gas installation, $k, l, m$ vacuum system

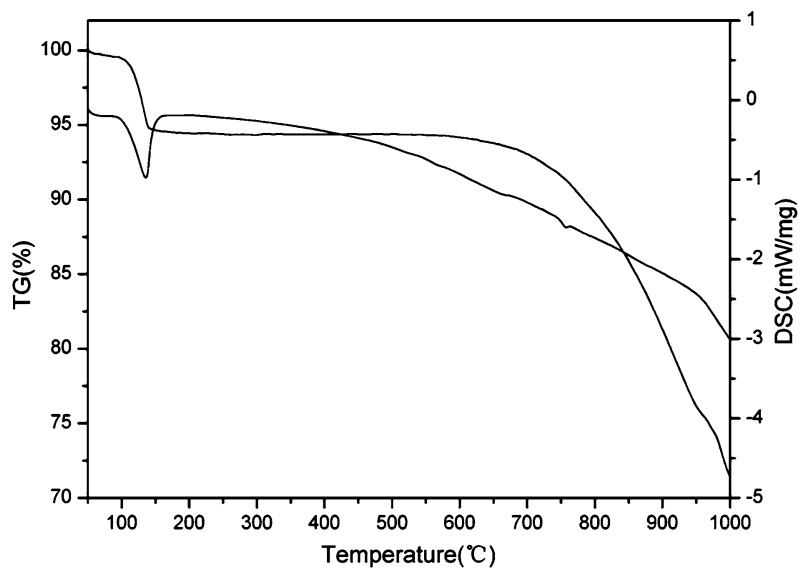

Fig. 2 TGA results of the glass- $\mathrm{CaCl}_{2}$ pellets

temperature of $\mathrm{PbCl}_{2}$ is below $600{ }^{\circ} \mathrm{C}$. It is far more below than Lead oxide (melting point $888^{\circ} \mathrm{C}$, boiling point $1740{ }^{\circ} \mathrm{C}$ ). And the temperature by adjusting the pressure of the atmosphere around reaction are controlled. Thermodynamic interactions between the glass and the chlorination agents at $600{ }^{\circ} \mathrm{C}$ were calculated by following quation.

$$
\begin{gathered}
\mathrm{CaCl}_{2}+\mathrm{PbSiO}_{3}=\mathrm{CaSiO}_{3}+\mathrm{PbCl}_{2} \\
\Delta G=-13.65 \mathrm{~kJ} \cdot \mathrm{mol}^{-1}\left(600^{\circ} \mathrm{C}\right)
\end{gathered}
$$

Therefore, $\mathrm{CaCl}_{2}$ was selected as effective chlorinating agent in the following study. Comparing with the low $\mathrm{SiO}_{2}$ content solid wastes, the special stable structure which is $\mathrm{PbO}(1-x) \mathrm{SiO}_{2}$ of CRT glass accelerates the chlorination process because the formation of $\mathrm{CaSiO}_{3}$ is thermodynamically favored.

To demonstrate the beginning temperature of the reaction, thermogravimetric analysis was used. Figure 2 is the result of thermogravimetric analysis of the pellets. There is a quick mass loss at $135.91{ }^{\circ} \mathrm{C}$ which means the combined water in the pellets evaporate from its solder. With the increase of the temperature, the reaction happened at

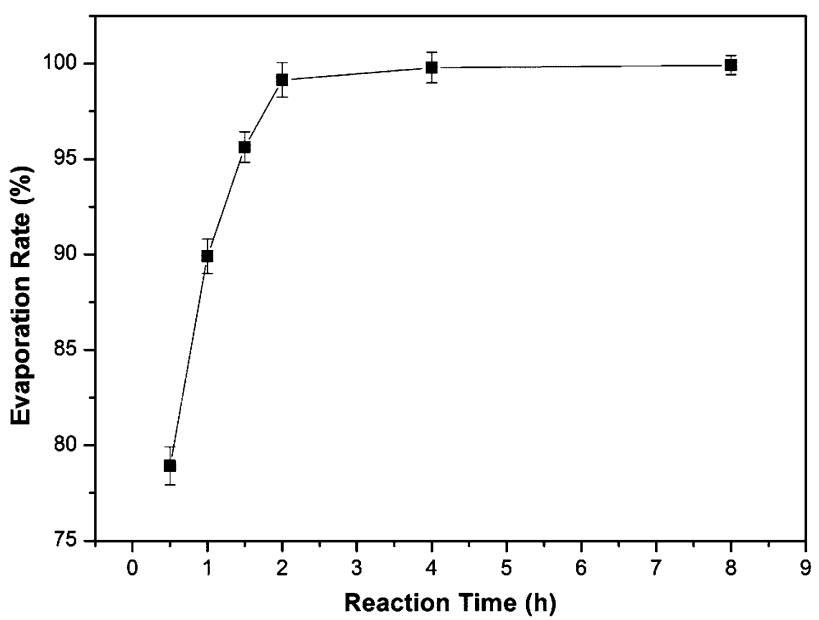

Fig. 3 Lead evaporation ratio as a function of treatment time of vacuum chlorination process in air

$600{ }^{\circ} \mathrm{C}$. And the weight of the pellet decreased at $600{ }^{\circ} \mathrm{C}$, and did not stop even at $1000{ }^{\circ} \mathrm{C}$. So the beginning temperature of the reaction is $600{ }^{\circ} \mathrm{C}$, and it continued when the temperature came to $1000{ }^{\circ} \mathrm{C}$. Because the TGA method did not maintain in a high temperature, the reaction was not finished during the test. The overall evaporation of the pellets needs more time in $1000{ }^{\circ} \mathrm{C}$, which cannot achieve under the current experiment equipment condition. Thus, the evaporation effects are increasing with temperature.

Effects of various parameters on lead removal efficiencies

Figure 3 illustrates the effects of holding time on lead evaporation ratio. Evaporation rate is increasing with the holding time. In two hours, reaction almost complicated. The optimal evaporation ratio of lead reached $99.1 \%$. Figure 4 shows the impact of different system pressure and 


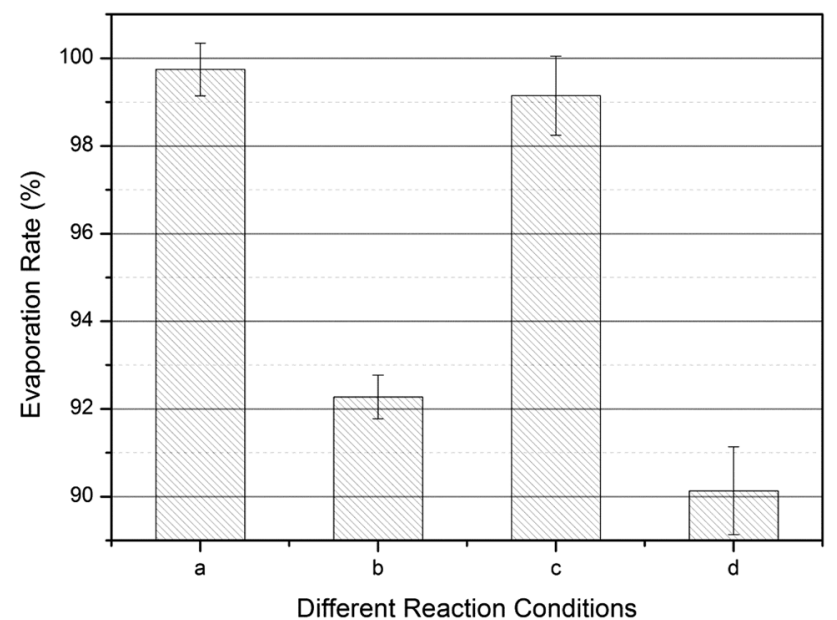

Fig. 4 Impact of different system pressure and atmosphere on evaporation rate after vacuum chlorination at $1000{ }^{\circ} \mathrm{C}$ hold for $2 \mathrm{~h}$. $a$ argon gas, $600 \pm 50 \mathrm{~Pa} ; b$ argon gas, 1 atm; $c$ air, $600 \pm 50 \mathrm{~Pa}$; $d$ air, $1 \mathrm{~atm}$

atmosphere on evaporation rate after two hours treatment in $1000{ }^{\circ} \mathrm{C}$. Lead chloride evaporates easier in vacuum than in atmospheric pressure. Considering the practical utilization of this technique, the use of argon gas is not encouraged during the process. Thus, the optimum operation temperature, treatment time, system pressure were $1000{ }^{\circ} \mathrm{C}, 2 \mathrm{~h}, 600 \pm 50 \mathrm{~Pa}$, respectively, and the preferable atmosphere was air.

\section{Evaluation of the detoxification effects}

\section{Element composition of original CRT glass and the residues}

Figure 5 shows the XRF results for original glass and the residue in optional reaction condition. The content of lead was reduced effectively to a low concentration. Sodium and potassium are all removed thoroughly from the lead glass because of in vacuum condition their chlorides are easy to volatile under reaction temperature. In addition, because of the use of chlorination agent, calcium in the residue is dramatically higher than in original glass. Other component of major elements, for instance, oxygen, silicon, aluminum, magnesium, did not change significantly. There is a few excess chlorine remain in the residue. According to main components of cement [34], which is familiar with major components of the residue, treated waste CRT funnel glass with a density $\left(\sim 2400 \mathrm{~kg} / \mathrm{m}^{3}\right)$ can be used as a potential material for production of concrete and cement. Being a calcium silicate mineral, it contributes calcium in ceramic glaze mixes.

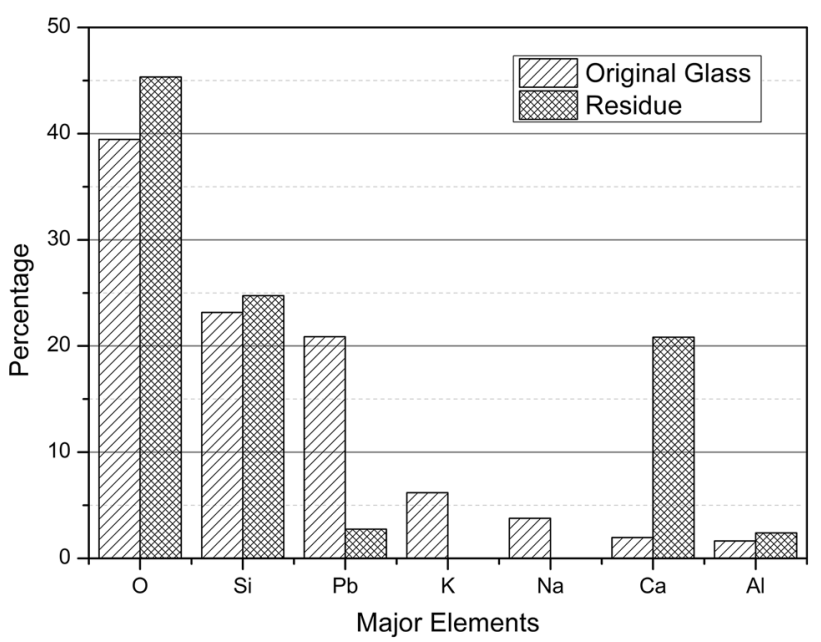

Fig. $5 \mathrm{XRF}$ results of the original lead glass and residue after vacuum chlorination at $1000{ }^{\circ} \mathrm{C}$ hold for $1 \mathrm{~h}$

\section{Evaluation of microstructure of the residues}

According to XRD results, The $\mathrm{CaSiO}_{3}$ crystals in the residues have two kinds of crystalline phases, which are wollastonite-2 $\mathrm{M}$ and wollastonite-1A. With SEM test, the surface of the residue could be presented. According to the lattice parameter of these crystals, the wollastonite- $2 \mathrm{M}$ is long striped and wollastonite- $1 \mathrm{~A}$ is flat. Different crystal structures lead to different functions during its further utilization. Figure $6 \mathrm{a}$ is the original look of CRT glass which composed by lots of irregular glass particles. In Fig. 6b crystal form of the residue is complex and made of two different kinds of crystals. Figure $6 \mathrm{c}$ shows the same result with Fig. $6 \mathrm{~b}$ that the residue is made of two kinds of crystals. However, when the atmosphere changes to air, the wollsatonite- $2 \mathrm{M}$ dominates the residue which is obvious in Fig. 6d. When wollsatonite-2 $\mathrm{M}$ dominates the residue, there were plenty of micron-sized pore structure in the residue. Amorphous material transported into regular arrangement crystal during the chlorination volatilization process. This arrangement of crystal structure enhanced the strengthen and decreased the density of the residue, which benefits its further application.

\section{Evaluation of the detoxification effects}

After the treatments, the residues were found to be nonhazardous wastes, since the leaching concentrations of lead from the treated residues by TCLP test were in the range of $1.69-2.11 \mathrm{mg} / \mathrm{L}$, lower than the TCLP lead threshold by USEPA $(5 \mathrm{mg} / \mathrm{L})$. These results indicate that calcium silicate mineral in the residue could convert into valuable resource safely. The BET experiment showed us 

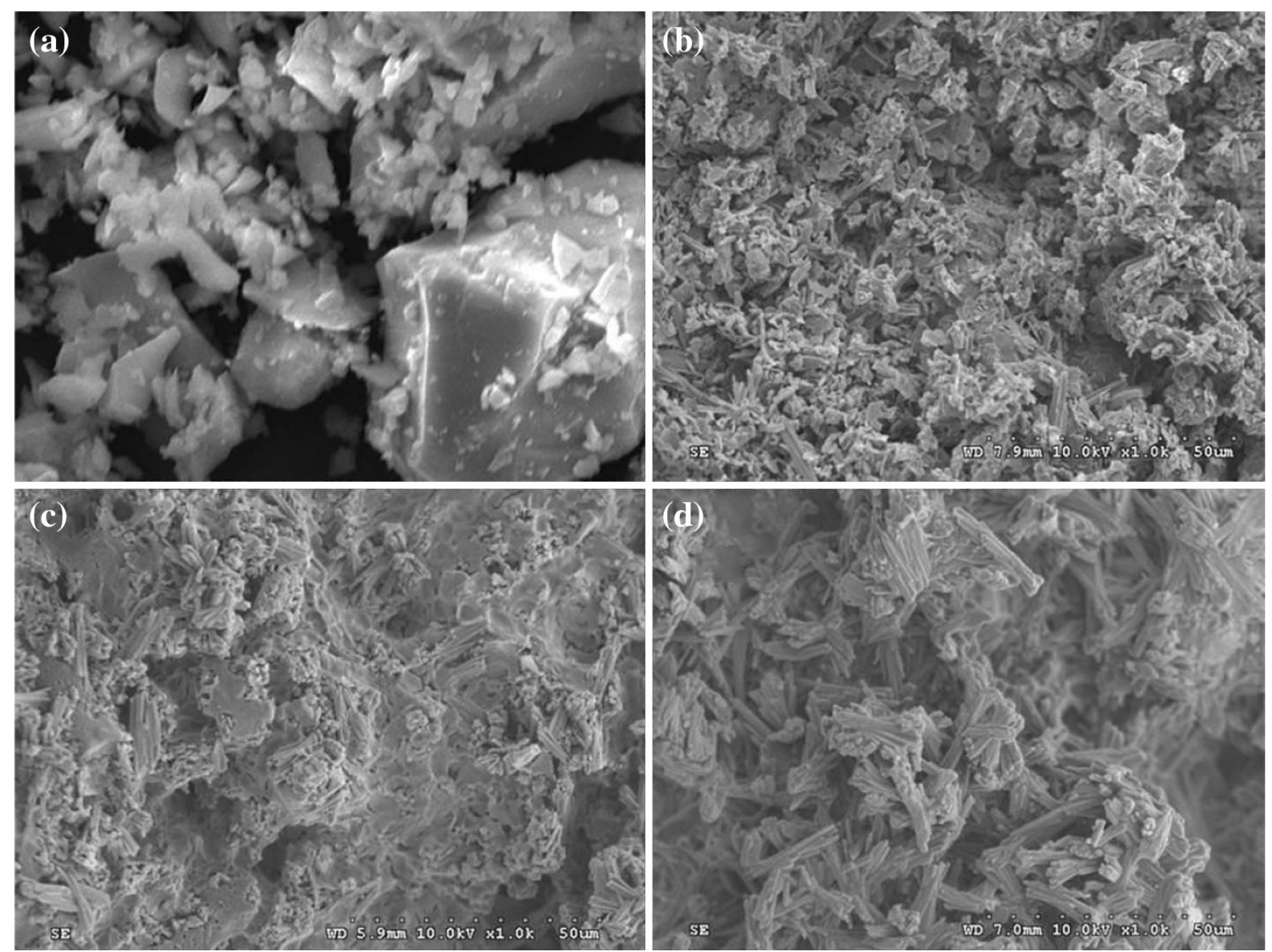

Fig. 6 SEM photographs of the CRT glass and the residues treated at $1000{ }^{\circ} \mathrm{C}$ hold for $1 \mathrm{~h}$. a Original CRT glass; $\mathbf{b}$ argon gas, $600 \pm 50 \mathrm{~Pa}$; c argon gas, 1 atm; $\mathbf{d}$ air, $1 \mathrm{~atm}$

that specific surface area of the residues was $7.248 \mathrm{~m}^{2} / \mathrm{g}$. The physical properties of the residue are also measured. Maximum load of the residue particles was $1136.82 \mathrm{~N}$, and compressive strength of it was 14.47 MPa. From these physical characters, we infer that residues can be used as aggregate in architecture progress and other areas.

\section{Conclusions}

Chlorination volatilization was an effective approach for the detoxification of waste lead glass. The optimal operation parameters were $1000{ }^{\circ} \mathrm{C}, \quad 2 \mathrm{~h}, \quad$ and $600 \pm 50 \mathrm{~Pa}$, respectively. In addition, the process was demonstrated as an environmental friendly method for producing. The residue could be used for wollastonite synthesis.

Acknowledgments This work was financed by the National Natural Science Foundation of China (21077120, 51278485), the Strategic Priority Research Program of the Chinese Academy of Sciences (XDB05050200), and the Science Promotion Program of Research Center for Eco-Environmental Sciences, CAS (YSW2013B05).

\section{References}

1. Xu Q, Li G, He W, Huang J, Shi X (2012) Cathode ray tube (CRT) recycling: Current capabilities in China and research progress. Waste Manag 32:1566-1574

2. Gregory JR, Nadeau M-C, Kirchain RE (2009) Evaluating the economic viability of a material recovery system: The case of Cathode Ray Tube glass. Environ Sci Technol 43:9245-9251

3. Mear F, Yot P, Cambon M, Ribes AM (2005) Elaboration and characterisation of foam glass from cathode ray tubes. Adv Appl Ceram 104:123-130

4. Wang PW, Zhang LP (1996) Structural role of lead in lead silicate glasses derived from XPS spectra. J Non Cryst Solids 194:129-134

5. Witkowska A, Rybicki J, Di Cicco A (2005) Structure of partially reduced $\mathrm{xPbO}(1-\mathrm{x}) \mathrm{SiO} 2$ glasses: combined EXAFS and MD study. J Non Cryst Solids 351:380-393

6. Mear FO, Yot PG, Kolobov AV, Ribes M, Guimon M-F, Gonbeau D (2007) Local structure around lead, barium and strontium in waste cathode-ray tube glasses. J Non Cryst Solids 353:4640-4646

7. Schultz-Munzenberg C, Meisel W, Gutlich P (1998) Changes of lead silicate glasses induced by leaching. J Non Cryst Solids 238:83-90

8. Bonnet C, Bouquillon A, Turrell S, Deram V, Mille B, Salomon J, Thomassin JH, Fiaud C (2003) Alteration of lead silicate glasses due to leaching in heated acid solutions. J Non Cryst Solids 323:214-220 
9. Mizuno M, Takahashi M, Takaishi T, Yoko T (2005) Leaching of lead and connectivity of plumbate networks in lead silicate glasses. J Am Ceram Soc 88:2908-2912

10. Cailleteau C, Weigel C, Ledieu A, Barboux P, Devreux F (2008) On the effect of glass composition in the dissolution of glasses by water. J Non Cryst Solids 354:117-123

11. Keith A, Keesling K, Fitzwater KK, Pichtel J, Houy D (2008) Assessment of $\mathrm{Pb}, \mathrm{Cd}, \mathrm{Cr}$ and $\mathrm{Ag}$ leaching from electronics waste using four extraction methods. J Environ Sci Health A Tox Hazard Subst Environ Eng 43:1717-1724

12. Yuan W, Li J, Zhang Q, Saito F, Yang B (2013) Lead recovery from cathode ray tube funnel glass with mechanical activation. J Air Waste Manag Assoc 63:2-10

13. Ling T-C, Poon C-S, Lam W-S, Chan T-P, Fung KK-L (2012) Utilization of recycled cathode ray tubes glass in cement mortar for X-ray radiation-shielding applications. J Hazard Mater 199:321-327

14. Matamoros-Veloza Z, Rendon-Angeles JC, Yanagisawa K, Cisneros-Guerrero MA, Cisneros-Guerrero MM, Aguirre L (2008) Preparation of foamed glasses from CRT TV glass by means of hydrothermal hot-pressing technique. J Eur Ceram Soc 28:739-745

15. Yot PG, Mear FO (2011) Characterization of lead, barium and strontium leachability from foam glasses elaborated using waste cathode ray-tube glasses. J Hazard Mater 185:236-241

16. Mear F, Yot P, Cambon M, Caplain R, Ribes M (2006) Characterisation of porous glasses prepared from Cathode Ray Tube (CRT). Powder Technol 162:59-63

17. Habashi F (1997) Handbook of extractive metallurgy. Wiley, Weinheim

18. Jakob A, Stucki S, Struis RPWJ (1996) Complete heavy metal removal from fly ash by heat treatment: Influence of chlorides on evaporation rates. Environ Sci Technol 30:3275-3283

19. Chan CCY, Krik DW (1999) Behaviour of metals under the conditions of roasting MSW incinerator fly ash with chlorinating agents. J Hazard Mater 64:75-89

20. Wang KS, Chiang KY, Lin SM, Tsai CC, Sun CJ (1999) Effects of chlorides on emissions of toxic compounds in waste incineration: Study on partitioning characteristics of heavy metal. Chemosphere 38:1833-1849

21. Chan C, Jia CQ, Graydon JW, Krik DW (1996) The behaviour of selected heavy metals in MSW incineration electrostatic precipitator ash during roasting with chlorination agents. J Hazard Mater 50:1-13

22. Nowak B, Aschenbrenner P, Winter F (2013) Heavy metal removal from sewage sludge ash and municipal solid waste fly ash - a comparison. Fuel Process Technol 105:195-201

23. Fraissler G, Joller M, Mattenberger H, Brunner T, ObernBerger I (2009) Thermodynamic equilibrium calculations concerning the removal of heavy metals from sewage sludge ash by chlorination. Chem Eng Process 48:152-164

24. In-Kook Jun, Ju-Ha Song, Won-Yong Choi, Yong-Hag Koh, Hyoun-Ee Kim, Hae-Won Kim (2007) Porous hydroxyapatite scaffolds coated with bioactive apatite wollastonite glassceramics. Journal of the Ameican Ceramic Society 90:2703-2708

25. Xue Weichang, Liu Xuanyong, Zheng XueBin, Ding Chuanxian (2005) In vivo evaluation of plasma-sprayed wollastonite coating. Biomaterials 26:3455-3460

26. Nita Sahai, Michel Anseau (2005) Cyclic silicate active site and stereochemical match for apatite nucleation on pseudowollastonite bioceramic-bone interfaces. Biomaterials 26:5763-5770

27. Chen M, Zhang FS, Zhu J (2009) Lead recovery and the feasibility of foam glass production from funnel glass of dismantled cathode ray tube through pyrovacuum process. J Hazard Mater 161:1109-1113

28. Xing M, Zhang FS (2011) Nano-lead particle synthesis from waste cathode ray-tube funnel glass. J Hazard Mater 194:407-413

29. Yuan W, Li J, Zhang Q, Saito F (2012) Innovated application of mechanical activation to separate lead from scrap cathode ray tube funnel glass. Environ Sci Technol 46:4109-4114

30. Lee CH, Hsi CS (2002) Recycling of scrap cathode ray tubes. Environ Sci Technol 36:69-75

31. Musson SE, Jang YC, Townsend TG, Chung IH (2000) Characterization of lead leachability from cathode ray tubes using the toxicity characteristic leaching procedure. Environ Sci Technol 34:4376-4381

32. Epa US (1996) Test methods for evaluating solid waste. Office of Solid Waste, Washington, DC

33. Maruzen Co., Ltd. (1995) Chemical Handbook,The Chemical Society of Japan, second edn., 702-705

34. Ling TC, Poon CS (2012) A comparative study on the feasible use of recycled beverage and CRT funnel glass as fine aggregate in cement mortar. J Clean Prod 29-30:46-52 